\title{
Sosialisasi Learning Management System (LMS) Untuk Mendukung Pelaksanaan Pembelajaran Daring Pada Sekolah Menengah Kejuruan Negeri (SMKN) 2 Purwokerto
}

\author{
Nurul Hidayat*1, Lasmedi Afuan ${ }^{2}$, Nur Chasanah ${ }^{3}$ \\ 1,2,3Informatika, Fakultas Teknik, Universitas Jenderal Soedirman \\ *e-mail: $\underline{\text { nurul@unsoed.ac.id }}^{1}{ }^{\text {lasmedi.afuan@unsoed.ac.id }}{ }^{2}{ }_{2} \underline{\text { nur.chasanah@unsoed.ac.id }}^{3}$
}

\begin{abstract}
Abstrak
Di masa pandemi Covid-19, Menteri Pendidikan dan Kebudayaan mengeluarkan surat edaran no 4 tahun 2020 tentang pelaksanaan kebijakan pendidikan dalam masa darurat penyebaran Covid-19. Poin no 2 pada surat edaran tersebut berisi mengenai pelaksanaan belajar dari rumah melalui pembelajaran daring. Guru dan siswa diminta untuk melaksakan proses belajar mengajar melalui pembelajaran daring/jarak jauh. Proses pembelajaran dilaksanakan secara online sychronous atau online asynchronous. Untuk sychronous dapat dilaksanakan menggunakan berbagai platform online seperti Google Meet, Zoom, Microsoft Teams dan platform lainnya. Sedangkan, asyncronous dapat dilaksanakan dengan memanfaatkan platform seperti google classroom, schoology, moodle, dan berbagai learning management system lainnya. Sekolah Menengah Kejuruan Negeri (SMKN) 2 Purwokerto termasuk sekolah yang memanfaatkan media online synchronus Microsoft Teams agar proses pembelajaran tetap dapat berlangsung. Penggunaan platform online sangat membantu dalam pembelajaran daring, akan tetapi tetap harus didukung dengan penggunaan media pembelajaran online asynchronous. Salah satunya adalah Learning Mangement System (LMS). Pada kegiatan ini dilakukan sosialisasi penggunaan LMS, dilaksanakan sosialisasi LMS Moodle kepada guru SMKN 2 Purwokerto. Metode pelaksanaan yang digunakan adalah ceramah, praktik, dan diskusi. Hasil dari kegiatan ini, guru SMKN 2 Purwokerto memiliki pengetahuan tentang LMS, dan mampu menggunakan LMS untuk kegiatan pembelajaran secara asynchronous.
\end{abstract}

Kata kunci: covid-19, LMS, Online, Pendidikan

\begin{abstract}
In the covid-19 period, the Minister of Education and Culture issued circular letter no 4 of 2020 regarding the implementation of education policies in the emergency period of the spread of Covid-19. Point no 2 in the circular contains the implementation of learning from home through online learning. Teachers and students are asked to carry out the teaching and learning process through online/distance learning. The learning process is carried out synchronously online or asynchronously online. Synchronous can be implemented using various online platforms such as Google Meet, Zoom, Microsoft Teams and other platforms. Meanwhile, asynchronous can be implemented by utilizing Google Classroom, Schoology, Moodle, and various other learning management systems. The State Vocational High School (SMKN) 2 Purwokerto is a school that utilizes Microsoft Teams synchronous online media to continue learning. The use of online platforms is beneficial in online learning, but it must still be supported by using asynchronous online learning media. One of them is the Learning Management System (LMS). In this activity, socialization of the use of LMS was carried out, socialization of the Moodle LMS to teachers of SMKN 2 Purwokerto was carried out. The implementation method used is lecture, practice, and discussion. As a result of this activity, teachers of SMKN 2 Purwokerto know LMS and can use LMS for asynchronous learning activities.
\end{abstract}

Keywords: Covid-19, education, online, LMS

\section{PENDAHULUAN}

Covid-19 yang melanda Indonesia bahkan dunia telah mengubah cara manusia berinteraksi antara satu dengan lainnya. Covid-19 yang pertama kali didentifikasi di Kota Wuhan, provinsi Hubei, Cina[1] hingga saat ini belum menunjukkan tren penurunan, bahkan cenderung terus mengalami peningkatan jumlah orang yang terpapar Covid-19. Berdasarkan data yang diperoleh dari situs covid-19.id per 23 Juni 2021 tercatat sebanyak 2.000.000an Jiwa penduduk Indonesia yang terpapar Covid-19. 1.800.000an jiwa dinyatakan sembuh dan 50.000an jiwa meninggal dunia diakibatkan terpapar Covid-19. 
Interaksi yang selama ini dilakukan secara langsung dipaksa untuk dilakukan secara virtual (online). Hal ini terjadi semua bidang tidak terkecuali bidang pendidikan. Dengan adanya Covid-19 ini, sejak awal maret 2020, pemerintah Indonesia melalui kementerian pendidikan dan kebudayaan mengambil kebijakan melalui Surat Edaran (SE) Mendikbud no 4 tahun 2020 tentang pelaksanaan kebijakan pendidikan dalam masa darurat penyebaran CORONAVIRUS DISEASE (COVID-19). Pada poin 2 SE tersebut berisi tentang pelaksanaan belajar dari rumah melalui pembelajaran daring/jarak jauh. Hal ini dihimbau dalam upaya untuk pencegahan penyebaran Covid-19. Pembelajaran secara daring/online pada dasarnya dapat dikelompokkan menjadi 2 yaitu online synschronous dan online asynschronous[2].

Pembelajaran secara online synschronous dapat dilakukan melalui tatap muka secara virtual antara pendidik dan peserta, ini dapat dilaksanakan dengan memanfaatkan platform seperti Google Meet, Zoom, Microsoft Teams dan lainnya. Dalam pelaksanaannya, online synchronous mewajibkan pendidik dan peserta didik melaksanakan tatap maya secara bersamaan. Sedangkan online asynschronous, merupakan proses pembelajaran yang dilaksanakan secara online akan tetapi tidak mewajibkan pendidik dan peserta didik bertatap maya secara langsung. Pembelajaran dilakukan oleh pendidik dengan mengunggah materi pelajaran, tugas dan aktivitas lainnya di sebuah media online yang dapat diakses oleh peserta didik. Pelaksanaan model ini dilakukan pada waktu yang berbeda antara peserta didik satu dengan yang lainnya.

SMKN 2 Purwokerto (Gambar 1) merupakan salah satu sekolah menengah kejuruan unggulan yang ada di kota Purwokerto. Sebagai bagian satuan pendidikan yang berada dibawah Kemendterian Pendidikan dan Kebudayaan, SMKN 2 turut berpartisipasi aktif dalam melaksanakan kebijakan pemerintah dalam upaya pencegahan penyebaran di masa pandemi Covid-19. Pembelajaran daring yang sudah dilakukan oleh SMKN 2 Purwokerto adalah online syncronous dengan menggunakan Microsoft Teams, dimana peserta didik (siswa) hadir secara online untuk mendengarkan dan berdiskusi dengan pengajar (guru).

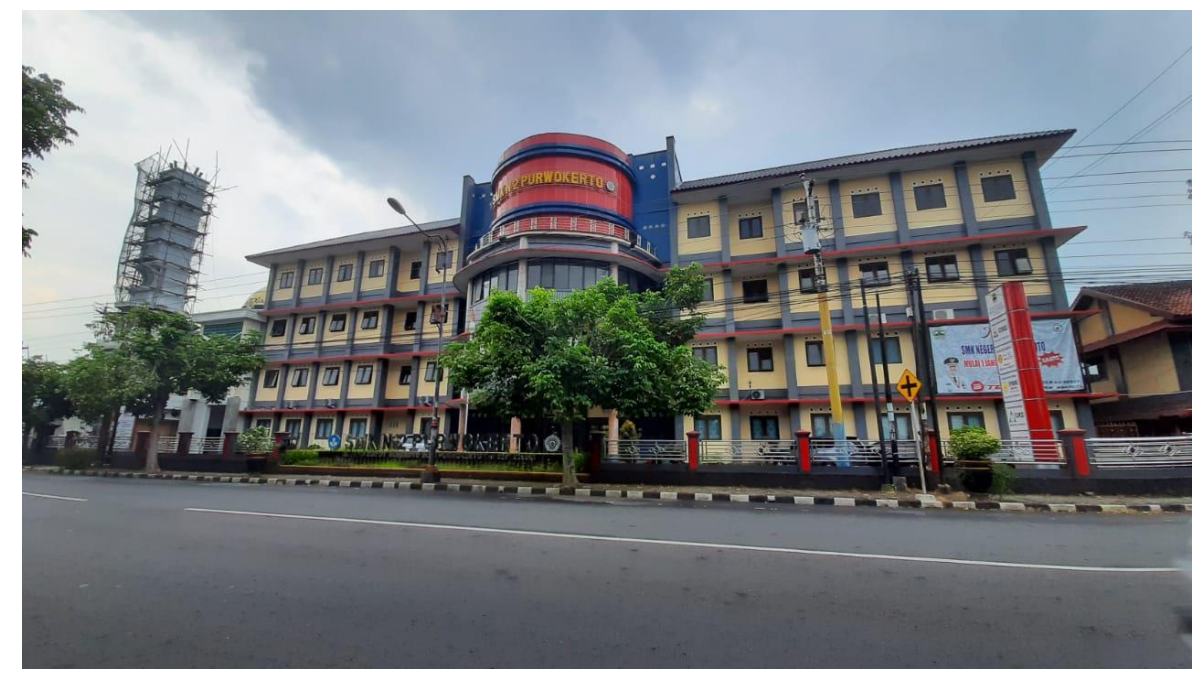

Gambar 1. Gedung SMKN 2 Purwokerto (tampak depan)

Akan tetapi, penggunaan Microsoft Teams masih dirasa kurang oleh para guru dan siswa, diperlukan platform online yang dapat digunakan sebagai suplemen bagi guru untuk menyampaikan materi, tugas, dan aktivitas pembelajaran lainnya (online asynchronous). SMKN 2 Purwokerto hingga saat ini belum memiliki LMS yang dapat digunakan untuk menunjang pembelajaran online asynchronous.

Berdasarkan permasalahan yang dihadapai oleh SMKN 2 Purwokerto, tim pelaksana pengabdian kepada masyarakat UNSOED telah mengembangkan LMS menggunakan moodle untuk digunakan di SMKN 2 Purwokerto, LMS ini diharapkan dapat membantu pihak SMKN 2 dalam melaksanakan pembelajaran online asynchronous selama pandemi Covid-19. Untuk memberikan pemahaman penggunaan LMS yang telah dikembangkan, maka dilakukan perlu 
dilaksanakan kegiatan sosialisasi penggunaan LMS. Kegiatan sosialisasi LMS ini bertujuan untuk memberikan pemahaman kepada guru SMKN 2 Purwokerto mengenai penggunaan LMS yang telah dikembangkan. Kegiatan sosialisasi meliputi Kegiatan sosialisasi sejenis telah dilakukan oleh beberapa tim PKM [3][4][5][6][7][8].

\section{METODE}

Kegiatan sosialisasi ini dilakukan dengan menggunakan metode ceramah, praktik, dan diskusi. Sosialisasi dilakukan kepada para Guru SMK N 2 Purwokerto. Adapun penjelasan dari masing-masing metode antara lain:

1. Ceramah

Metode ceramah digunakan untuk menyampaikan materi secara terperinci. Materi yang disampaikan antara lain pengantar mengenai pembelajaran daring di masa pandemi Covid19, pengenalan LMS, pengenalan Moodle, dan pengenalan LMS SMK Negeri 2 Purwokerto yang telah dikembangkan

2. Praktik

Teknik ini digunakan untuk memberikan demonstrasi penggunaan LMS kepada para SMK Negeri 2 Purwokerto, sehingga para guru dapat langsung menggunakan LMS dengan baik dan benar

3. Diskusi

Diskusi dilakukan untuk mengakomodir pertanyaan-pertanyaan dan masukan yang muncul dari pada peserta pada saat dilakukannya sosialiasasi.

\section{HASIL DAN PEMBAHASAN}

Kegiatan Sosialisasi Learning Management Systems (LMS) untuk mendukung pelaksanaan pembelajaran daring pada SMKN 2 Purwokerto dilaksanakan pada tanggal 07 Juni 2021 pukul 08.00-12.00. Kegiatan sosialisasi dilaksanakan secara offline di ruang aula SMKN 2 Purwokerto dengan tetap menerapkan protokol kesehatan sesuai dengan himbauan dari pemerintah (3 M). Pada kegiatan tersebut dihadiri wakil kepala sekolah dan guru SMKN 2 Purwokerto. Kegiatan sosialisasi dilakukan oleh tim dosen Universitas Jenderal Soedirman yang terdiri dari 3 orang dosen yaitu 1) Dr. Nurul Hidayat, M.Kom; 2) Dr. Lasmedi Afuan, ST.,M.Cs; dan 3) Nur Chasanah, S.Kom.,M.Kom.

Kegiatan sosialisasi dimulai dengan penyampai materi mengenai LMS. Materi tersebut disampaikan oleh Bapak Dr. Nurul Hidayat, M.Kom. Pemaparan yang disampaikan adalah pemahaman dan implementasi e-learning. Dengan adanya Covid-19 ini, dunia pendidikan dipaksa untuk bertransformasi lebih cepat dari waktunya. Pendidikan mengalami pergeseran dari mode evolusi menjadi revolusi. Guru pada zaman milenial harus mampu beradaptasi dengan perubahan model pembelajaran. Dari guru yang BITEK (bisu teknologi informasi) harus berubah menjadi guru yang CANTIK (canggih teknologi informasi). Tantangan dunia pendidikan yang terjadi diseluruh dunia adalah bagaimana mempersiapkan generasi abad ke-21 oleh guru abad ke-20 melalui sekolah abad ke-19 dengan menggunakan metode pembelajaran abad ke-18.

Untuk dapat memahami dan mendalami fenomena pembelajaran abad ke-21dibutuhkan kemauan dari semua guru dan siswa untuk membuka hati (open heart) dan membuka pikiran (open mind). Saat ini, guru harus mampu untuk memposisikan teknologi sebagaimana mestinya. Pemanfaatan e-learning dalam pembelajaran merupakan suatu keniscayaan. Dengan menggunakan e-learning dapat memberikan akses dan fasilitas kepada siswa untuk membangun pengetahuannya secara mandiri dan terarah, serta memberikan peran penting guru sebagai perancang, pemantik, fasilitator, dan motivator pembelajaran.

Gambar 2 merupakan dokumentasi dari pemaparan materi yang disampaikan oleh Bapak Dr. Nurul Hidayat, M.Kom mengenai pemahaman dan implementasi e-learning. Materi kedua disampaikan oleh Bapak Dr. Lasmedi Afuan, ST.,M.Cs. Pemaparan tersebut mendemosntrasikan mengenai LMS SMKN 2 Purwokerto yang telah dibuat (alamat Ims: 
http://lms.smknegeri2purwokerto.sch.id) . Tampilan dari halaman awal LMS dapat dilihat pada Gambar 4. Pada tahap awal, dipraktikkan kepada para guru bagaimana melakukan registrasi di LMS. Peserta sosialisasi diminta untuk mengisi halaman registrasi seperti ditampilkan pada Gambar 5. Untuk registrasi, pengguna diharuskan mengisi username, password, email, first name, surname, city/town, dan country. Jika sudah mengisikan, maka secara otomatis LMS akan mengirimkan notifikasi ke alamat email yang dimasukkan pada saat registrasi. Pengguna diwajibkan harus melakukan verifikasi untuk mengaktivasi akun LMS.

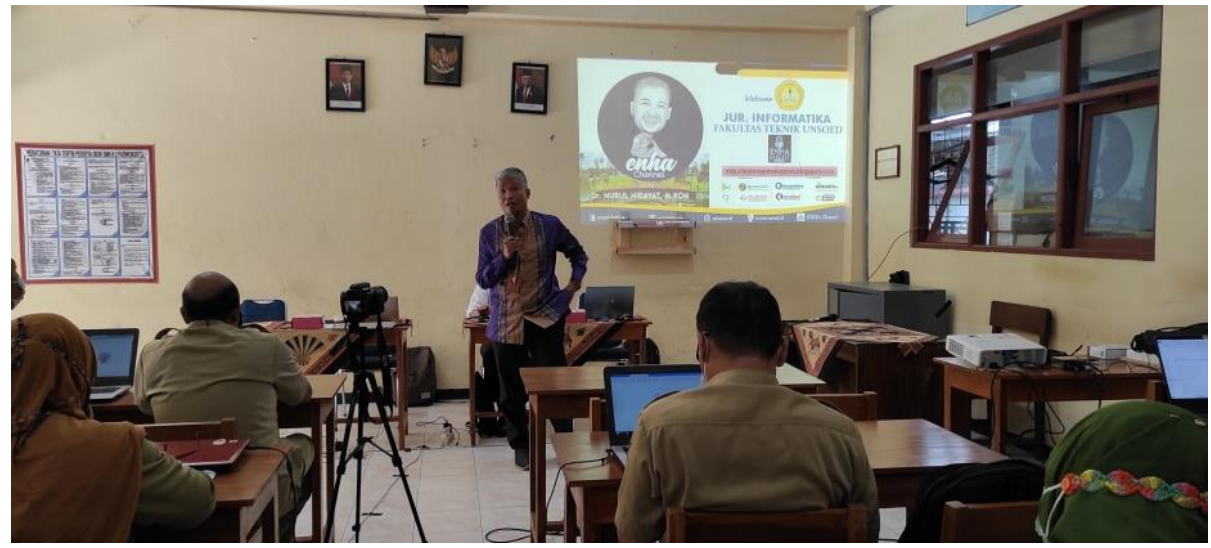

Gambar 2. Pengantar pemahaman dan implementasi e-learning (Sumber: Dokumentasi Pribadi, 2021)

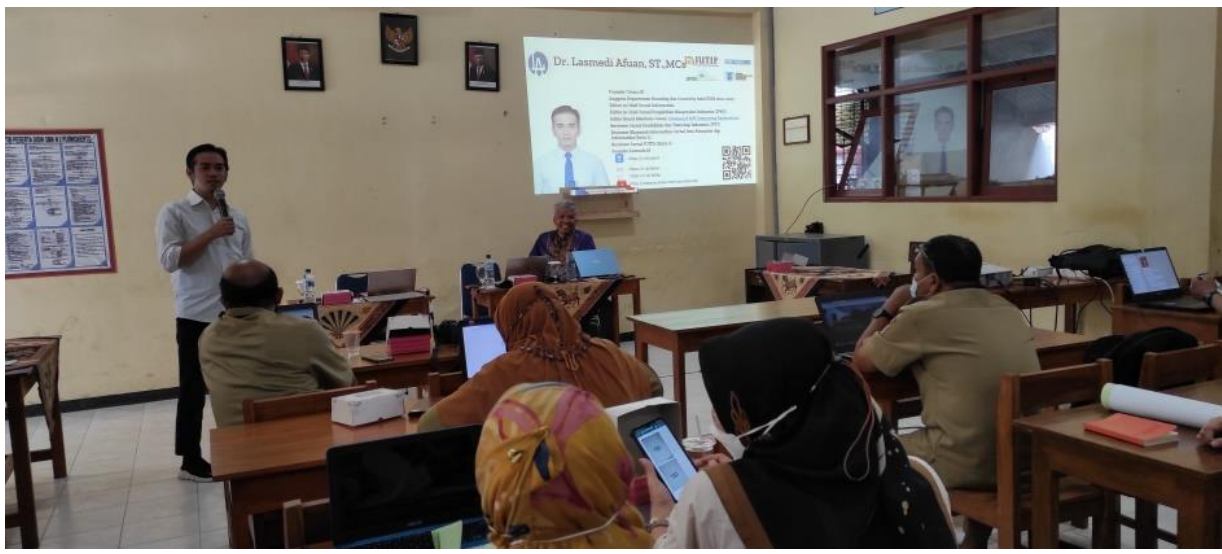

Gambar 3. Pemberian materi LMS SMK Negeri 2 Purwokerto (Sumber: Dokumentasi Pribadi, 2021)

Gambar 3 merupakan dokumentasi pemaparan materi demonstrasi LMS SMKN 2 Purwokerto didepan para guru-guru SMKN 2 Purwokerto. Materi sosialisasi dilanjutkan penyampaian mengenai fitur-fitur yang ada di LMS. Pada LMS guru bisa menambahkan, mengelola dan memodifikasi course mata pelajaran. Guru juga dapat menambahkan aktivitas dan resource ke dalam course. Aktivitas yang dapat ditambahkan seperti penugasan, kehadiran, chat, choice, H5P dan aktivitas lain. Sedangkan resource seperti book, file, folder, dan resource lainnya.

Gambar 4 merupakan tampilan awal dari website LMS SMKN 2 Purwokerto. Pada halaman tersebut terdapat beberapa menu yang bisa diakses oleh pengguna seperti menu create account dan login. Selain itu, terdapat beberapa kategori course yang diselenggarakan oleh SMKN 2 Purwokerto. Untuk melakukan registrasi akun baru, pengguna dapat mengklik menu create account, kemudian akan terlihat tampilan seperti pada Gambar 5.

Kegiatan sosialisasi diakhiri dengan penyampaian materi oleh ibu Nur Chasanah, S.Kom.,M.Kom. Materi yang disampaikan mengenai penggunaan activity dan resource di LMS SMKN 2 Purwokerto. 


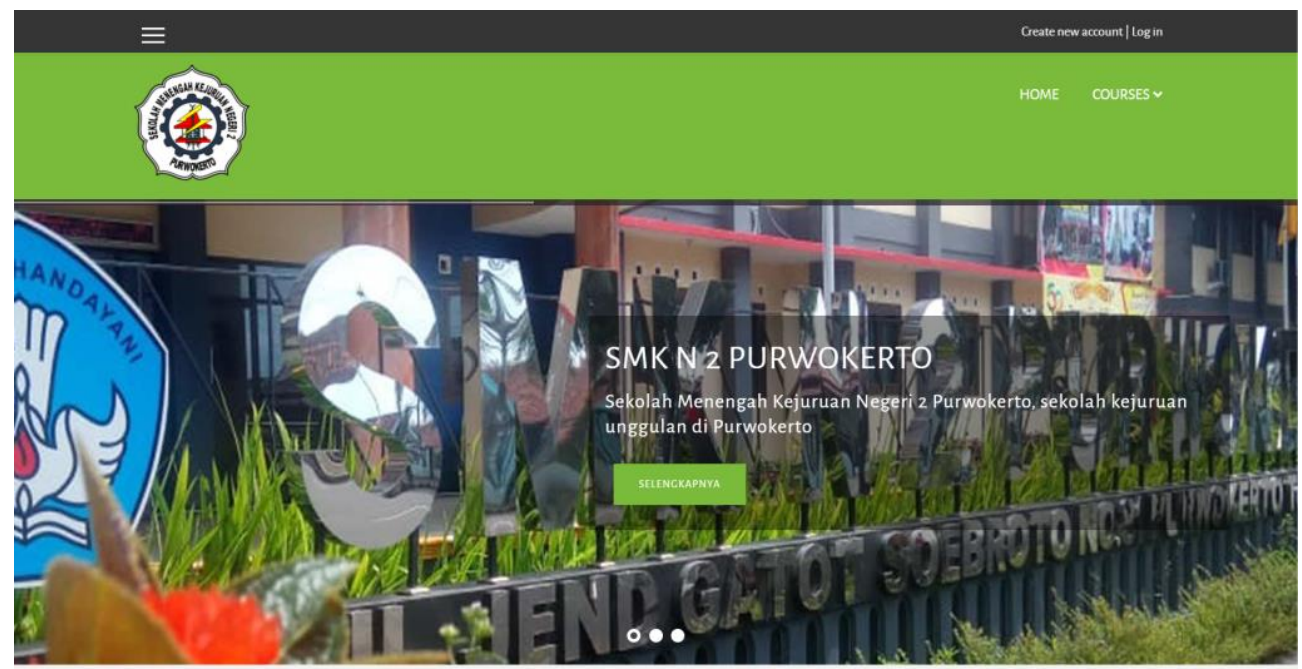

Gambar 4. Tampilan LMS SMK Negeri 2 Purwokerto

(Sumber: Dokumentasi Pribadi, 2021)

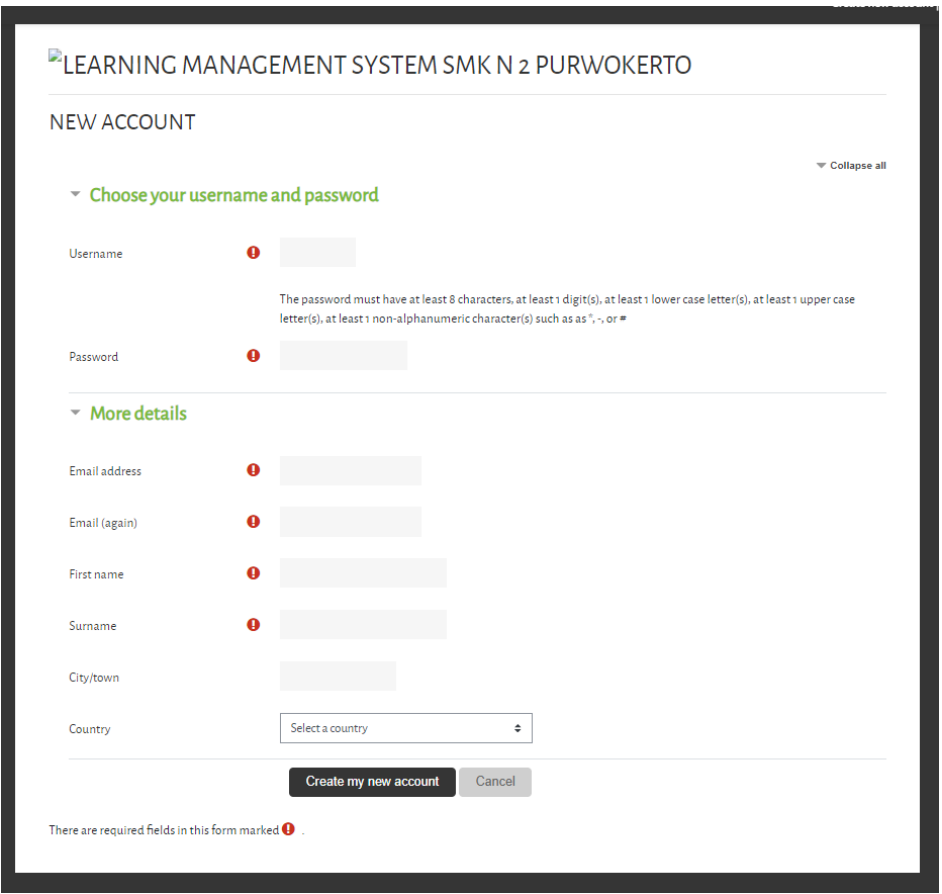

Gambar 5. Tampilan halaman registrasi

(Sumber: Dokumentasi Pribadi, 2021)

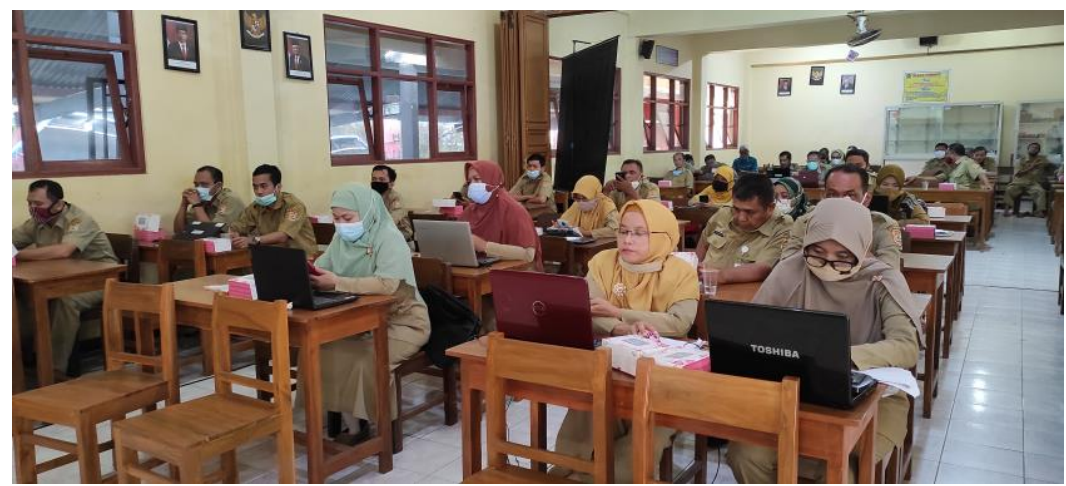

Gambar 6. Peserta Mencoba menggunakan LMS

(Sumber: Dokumentasi Pribadi, 2021) 
Gambar 6 merupakan aktivitas guru SMKN 2 Purwokerto mencoba praktik penggunaan LMS yang sudah dikembangkan oleh Tim pelaksana pengabdian masyarakat UNSOED. Pada akhir sesi pelatihan, tim pelaksana berkesempatan berfoto dengan salah satu peserta (guru) yang mengikuti kegiatan sosialisasi tersebut, seperti ditampilkan pada Gambar 7.

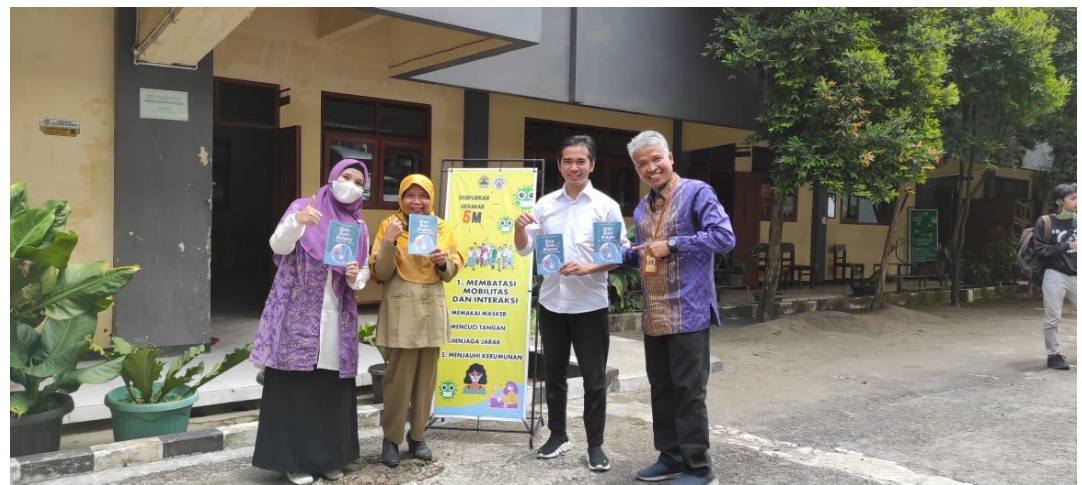

Gambar 7. Tim berfoto dengan salah satu guru SMKN 2 Purwokerto

(Sumber: Dokumentasi Pribadi, 2021)

Hasil dari kegiatan sosialisasi ini adalah guru SMKN 2 Purwokerto memiliki pemahaman mengenai e-learning dan pemanfaatan LMS yang telah dikembangkan.

\section{KESIMPULAN}

Kegiatan sosialisasi penggunaan LMS ditujukan bagi guru SMKN 2 Purwokerto, hal ini dilakukan untuk mengatasi permasalahan yang dihadapi para guru pada masa pandemi Covid19. Dengan adanya LMS, pembelajaran secara online asynchronous dapat dilakukan dengan mudah, sehingga guru dapat memberikan materi suplemen dan tugas-tugas. Guru mendapatkan pengetahuan mengenai e-learning dan bagaimana memanfaatkan LMS yang telah dikembangkan.

\section{UCAPAN TERIMA KASIH}

Terima kasih kepada Lembaga Penelitian dan Pengabdian Masyarakat (LPPM) Universitas Jenderal Soedirman yang telah memberikan support pendanaan dalam pelaksanaan kegiatan pengabdian kepada masyarakat tahun 2021. Ucapan terima kasih juga kepada Kepala Sekolah dan guru SMK N 2 Purwokerto, sehingga kegiatan pengabdian kepada masyarakat ini dapat berjalan dengan lancar.

\section{DAFTAR PUSTAKA}

[1] C. Sohrabi $d k k$., "World Health Organization declares global emergency: A review of the 2019 novel coronavirus (COVID-19)," Int. J. Surg., vol. 76, no. February, hal. 71-76, 2020, doi: 10.1016/j.ijsu.2020.02.034.

[2] I. W. G. Narayana, "Analisis Terhadap Hasil Penggunaan Metode Pembelajaran Synchronous dan Asynchronous," in Seminar Nasional Teknologi Informasi dan Multimedia, 2016, hal. 6-7.

[3] F. Xaverius, A. Perkasa, \& V. Christmantara, "Learning Management System ( LMS ) Menggunakan Google Classroom Bagi Guru SDK Mardiwiyata 2 Malang,” 2020.

[4] F. A. Yul \& N. Ramadani, "Sosialisasi Penggunaan Aplikasi Pembelajaran Online Untuk Guru SMK 5 di Kota Bengkulu,” Rangkiang J., vol. 2, no. 1, hal. 38-41, 2020. 
[5] L. C. Subadi, T. F. C. W. Sutrisno, I. G. Bagus, Y. Wiryakusuma, \& I. Ritunga, "Pelatihan Pembelajaran Berbasis E-Learning dengan Platform Learning Management System ( LMS ) di Fakultas Kedokteran Universitas Ciputra," J. Community Serv. Consort., vol. 1, no. 1, hal. 126-131, 2020.

[6] D. Friansah \& Y. Yanto, "Pelatihan Learning Mangament System-Schoology Bagi Guru MGMP Matematika SMS/SMK Kabupaten Musi Rawas," J. Cemerlang Pengabdi. pada Masy., vol. 2, no. 2, hal. 184-195, 2020.

[7] B. B. Albar, "Penerapan Learning Management System Melalui Modul Digital, Workshop, dan Pendampingan di Masa Pandemi Covid-19," hal. 394-402, 2020.

[8] D. Hadiansah $d k k$., "Sosialisasi Pemanfaatan Aplikasi Media Sosial Dalam Pembelajaran Daring Selama Pandemi Covid-19 Pada TK Al-Zharufa Kota Cimahi," Abdi Wiralodra, vol. 3, no. 1, hal. 1-16, 2021. 